\title{
Природные и техногенные факторы в формировании геохимии современных донных отложений малых озер г. Мурманска (Арктическая зона РФ)
}

\author{
Слуковский 3.И. ${ }^{1,2}$, Даувальтер В.А. ${ }^{1}$, Гузева А.В. ${ }^{1,3}$, Денисов Д.Б. ${ }^{1}$, Черепанов А.А. ${ }^{1}$ \\ ${ }^{1}$ Институт проблем промышленной экологии Севера КНЦ РАН, Anamumbl, slukovsky87@gmail.com \\ ${ }^{2}$ Институт геологии КарНЦ РАН, Петрозаводск \\ ${ }^{3}$ Институт озероведения РАН, Санкт-Петербург
}

Аннотация. В статье приводятся данные по содержанию химических элементов, включая тяжелые металлы, в современных донных отложениях трех малых озер г. Мурманска. Дается оценка уровня обогащения и обеднения элементами озерных осадков по сравнению с кларком земной коры, а также оценка накопления тяжелых металлов относительно фона региона исследования. Приводятся сведения, объясняющие влияние природных (в первую очередь, геологических) и антропогенных факторов на формирование геохимической специфики донных отложений озер г. Мурманска.

Ключевые слова: малые озера, донные отложения, химический состав, тяжелые металлы, урбанизация, Мурманск, Арктика.

\section{Nature and technogenic factors in the geochemistry of recent bottom sediments of small lakes of Murmansk (Arctic zone of Russia)}

\author{
Slukovskii Z.I. ${ }^{1,2}$, Dauvalter V.A. ${ }^{1}$, Guzeva A.V. ${ }^{1,3}$, Denisov D.B. ${ }^{1}$, Cherepanov A.A. ${ }^{1}$ \\ ${ }^{1}$ Institute of the North Industrial Ecology Problems of Kola Science Center of RAS, Apatity, slukovsky87@gmail.com \\ ${ }^{2}$ Institute of Geology of Karelian Research Centre of RAS, Petrozavodsk \\ ${ }^{3}$ Institute of Limnology RAS, Saint Petersburg
}

Abstract. Data on the content of chemical elements, including heavy metals, in the recent sediments of the three lakes of Murmansk city are presented. Assessment of the level of enrichment and impoverishment of lake sediments by the elements in comparison with the average content of elements in the Earth's continental crust as well as an assessment of accumulation of heavy metals regarding the background is given. The evidence of the influence of nature (firstly, geological) and technogenic factors on the geochemistry features of the studied urban lake sediments are presented.

Key words: small lakes, bottom sediments, chemical composition, heavy metals, urbanization, Murmansk, Arctic.

\section{Введение}

Городская среда формирует специфические аномалии в геохимии депонирующих сред, таких как донные отложения (ДО) водных объектов, в том числе озер. В первую очередь, это происходит под воздействием выбросов промышленных предприятий и транспорта. Основными индикаторами техногенного преобразования окружающей среды на примере ДО озер служат тяжелые металлы (ТМ) и сопутствующие им химические элементы (Даувальтер и др., 2018). С другой стороны, на геохимии озерных осадков может сказываться и природное влияние, в первую очередь вызванное миграцией элементов из горных пород территории водосбора. В зависимости от ряда факторов, к числу которых можно отнести влияние климата и рельефа, интенсивности выветривания геологических формаций и близости источников антропогенных выбросов, будут выделяться доминирующие процессы, влияющие на накопление вещества в ДО озер. Основой целью данного исследования является оценка уровня накопления химических элементов в современных ДО трех озер г. Мурманска с выделением природных и техногенных факторов, влияющих на геохимическую специфику процесса седиментации в выбранных урбанизированных водоемах. 


\section{Район и методы исследования}

Мурманск - столица Мурманской области и крупнейший город мира, полностью расположенный за Полярным кругом, с населением около 300 тыс. человек. На территории Мурманска и вблизи него расположено несколько десятков озер, имеющих как хозяйственно-бытовое, так и рекреационное значение для жителей и гостей города. В данной работе для анализа геохимических особенностей ДО озер были выбраны три водоема, находящихся в разных частях Мурманска: оз. Северное, оз. Семеновское и оз. Окуневое (рис. 1).

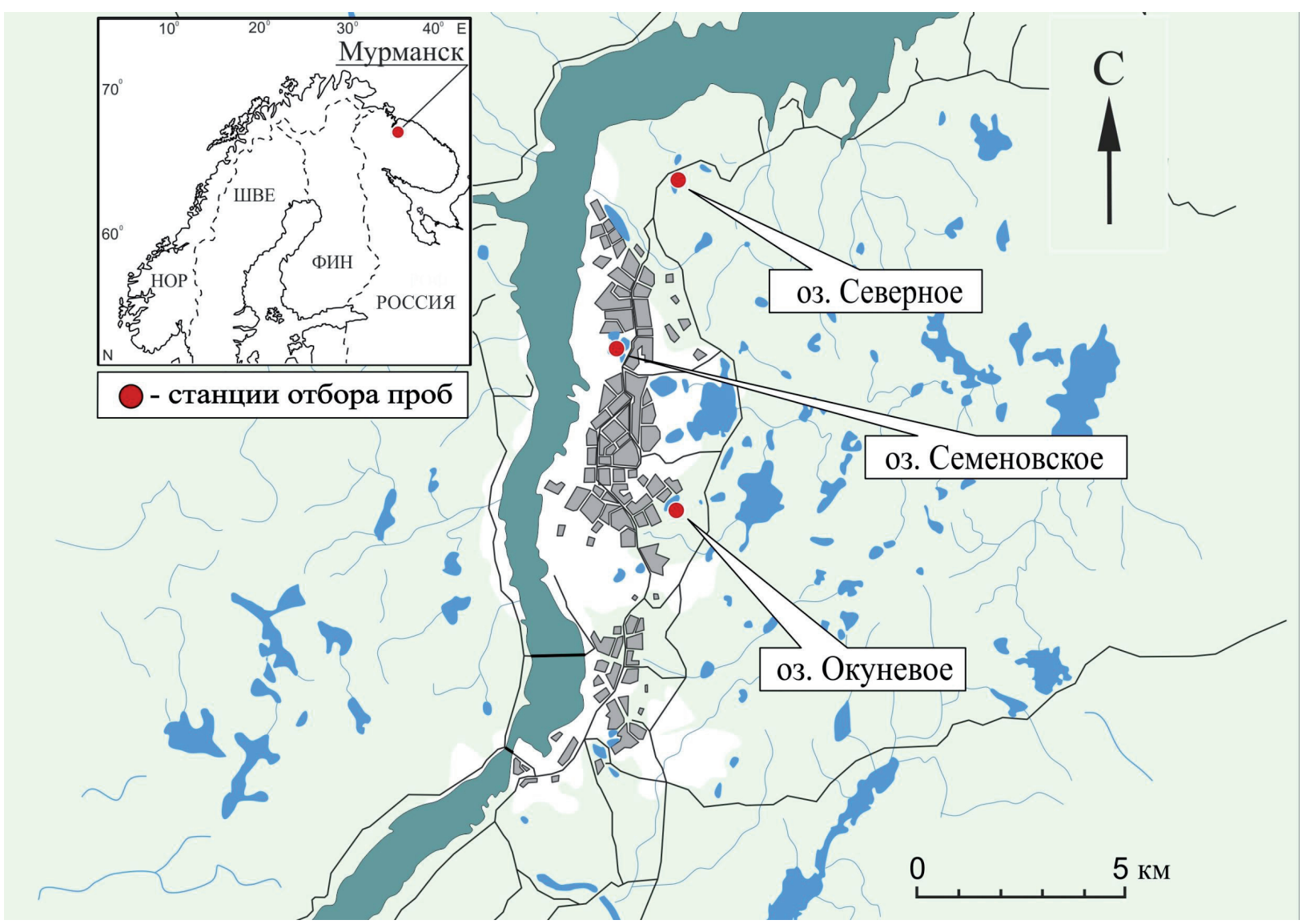

Рис. 1. Район исследования. Fig. 1. Study area.

Отбор проб ДО озер был произведен в апреле 2019 года со льда. С каждого водного объекта в районе максимальной глубины при помощи отборника гравитационного типа Limnos было отобрано по одной колонке ДО. После отбора каждая колонка делилась на последовательные слои через 1 см, пробы складировались в пластиковые контейнеры, которые подписывались и укладывались в сумку-холодильник. Далее пробы доставлялись в лабораторию. Просушивание образцов проб ДО перед анализом до воздушно-сухого состояния проводилось при комнатной температуpe, a до абсолютно-сухого - в сушильном шкафу при температуре около $110^{\circ} \mathrm{C}$. Аналитические исследования проводились на базе Института геологии Карельского научного центра РАН (Петрозаводск). Для оценки валовых концентраций элементов проводилось разложение образцов ДО путем кислотного вскрытия в открытой системе с использованием смеси $\mathrm{HF}, \mathrm{HNO}_{3}$ и $\mathrm{HCl}$. Содержание химических элементов в пробах ДО озер определяли масс-спектральным методом на приборе XSeries-2 ICP-MS.

\section{Результаты и обсуждение}

Анализ содержания 41 химического элемента, включая ТМ, в ДО озер Северного, Семеновского и Окуневого выявил (рис. 2), что в целом все изучаемые отложения обогащены $\mathrm{Cu}, \mathrm{Zn}, \mathrm{Mo}$, 


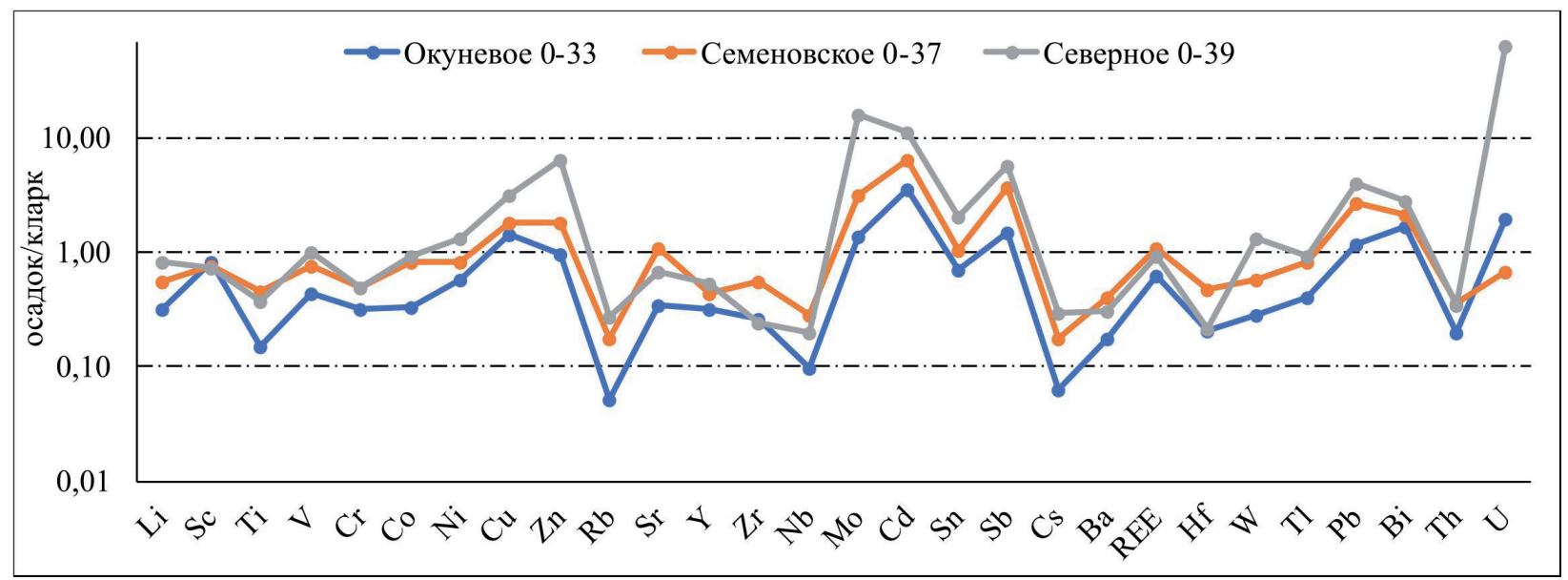

Рис. 2. Медианный уровень накопления химических элементов в ДО озер г. Мурманска относительно кларка континентальной земной коры (цифры после названия озер на графике означают диапазон глубины проникновения в ДО каждого из водоемов).

Fig. 2. The median level of accumulation of chemical elements in the sediments of the Murmansk lakes regarding to the average of their content in the Earth's continental crust.

$\mathrm{Cd}, \mathrm{Sb}, \mathrm{Pb}$ и Вi относительно среднего содержания (кларка) этих элементов в континентальной земной коре (Wedepohl, 1995). Кроме того, в осадках оз. Северного и оз. Окуневого отмечено повышенное содержание U, причем для ДО оз. Северного установлены более чем 100-кратные превышения кларка. С другой стороны, изучаемые осадки значительно обеднены Rb, Nb, Cs, Hf и Th (pис. 2).

Учитывая, что исследованные озера расположены в зоне прямого воздействия техногенных выбросов от промышленных предприятий и транспорта г. Мурманска, то очевидно, что такие элементы как $\mathrm{Cu}, \mathrm{Zn}, \mathrm{Mo}, \mathrm{Cd}, \mathrm{Sb}, \mathrm{Pb}$ и Вi обогащали ДО городских водоемов в результате антропогенного влияния на протяжении как минимум последних 150-200 лет. Динамика усиления техногенной нагрузки на окружающую среду города хорошо отражена в вертикальном распределении ТМ и ряда сопутствующих элементов в колонках ДО каждого из исследованных озер (рис. 3). Подобное поведение ТМ в озерных осадках озер, находящихся в зоне антропогенного влияния, - характерное явление, отмечаемое во многих исследованиях по всему миру, включая северные регионы России (Моисеенко и др., 2000; Escobar et al., 2013; Kuwae et al., 2013; Слуковский, Даувальтер, 2019). Следует обратить внимание, что своеобразным маркером влияния ТЭЦ г. Мурманска, работающей на мазуте, на экосистемы городских озер, является резкое и многократное увеличение $\mathrm{V}$ и $\mathrm{Ni}$, содержащихся в нефтепродуктах в виде примесей, в самых верхних слоях ДО озер Северного, Семеновского и Окуневого (рис. 3). Аналогичные закономерности ранее были отмечены в ДО городского озера на территории г. Петрозаводска (Карелия), где ТЭЦ также работает на мазуте (Слуковский, 2018).

Необычное поведение U и сопутствующего ему Мо в изученных ДО озер, особенно в осадках оз. Северного (рис. 4), можно объяснить влиянием коренных пород северо-западной части Мурманской области, так как ранее в этих образованиях отмечались урановые оруденения (Савицкий и др., 1995). При этом с U в обозначенных породах, преимущественно магматического и метаморфического генезиса, хорошо коррелируют и другие элементы, например, Мо. Это объясняет тесную взаимосвязь U и Мо в ДО оз. Северного. Следует добавить, что подобное повышенное накопление U в современных депонирующих средах не редкость в северных широтах мира. Например, на территории стран Северной Америки и Европы широко распространены торфяники, обогащенные U (Миронов и др., 2015). Согласно исследованиям, геологические источники этого металла обычно находятся вблизи изученных болот и болотистых районов.

Кроме ТЭЦ на загрязнение окружающей среды г. Мурманска также оказывают влияние выбросы автомобильного и железнодорожного транспорта, пыль с портового угольного терминала, мусоросжигательный завод и другие предприятия. Нельзя исключать и воздействие дальнего пере- 


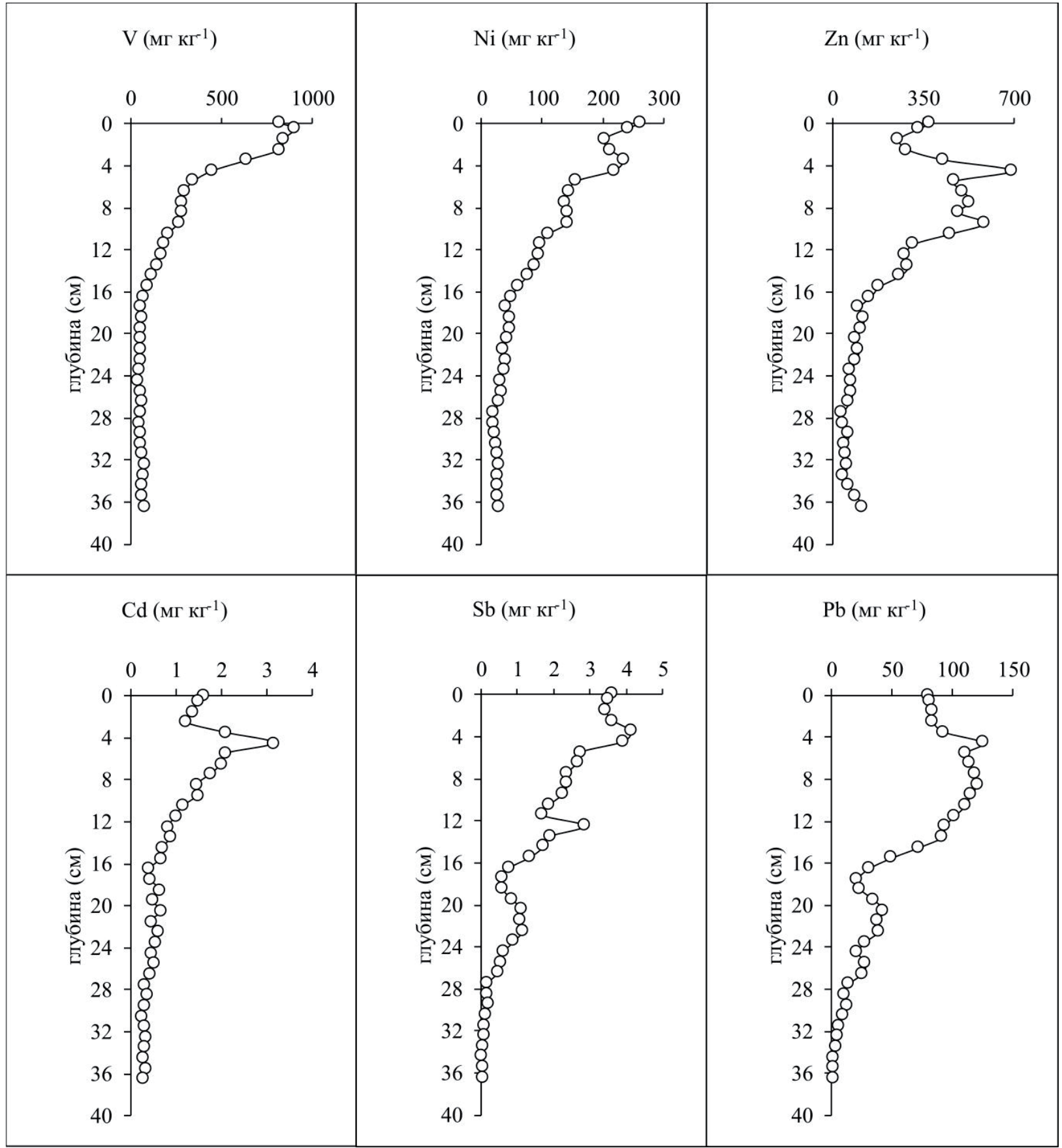

Рис. 3. Вертикальное распределение некоторых ТМ в колонке ДО оз. Семеновского (г. Мурманск).

Fig. 3. Vertical distribution of some heavy metals in the sediment core of Lake Semenovskoe (Murmansk).

носа загрязнителей со стороны крупных предприятий других районов Мурманской области (Слуковский, Даувальтер, 2019) и соседних с ней регионов России и Европы, учитывая, что ранее повышенное содержание $\mathrm{Cu}, \mathrm{Ni}, \mathrm{Co}, \mathrm{Pb}, \mathrm{Sn}, \mathrm{Bi}$ и $\mathrm{Sb}$ было установлено в современных ДО озер, расположенных в 60-70 км на северо-запад от района исследования (Даувальтер и др., 2018).

\section{Заключение}

Проведенные исследования геохимических особенностей ДО трех малых озер г. Мурманска с анализом вертикального распределения ТМ в колонках осадков выявили значительное техногенное влияние на высокий уровень накопления в ДО $\mathrm{Cu}, \mathrm{Zn}, \mathrm{Mo}, \mathrm{Cd}, \mathrm{Sb}, \mathrm{Pb}, \mathrm{V}$ и $\mathrm{Bi}$. Главным образом, на ухудшение экологической обстановки в городе влияют выбросы ТЭЦ, угольного терминала и транспорта. С другой стороны, установленное повышенное накопление U и Мо в ДО оз. Северно- 


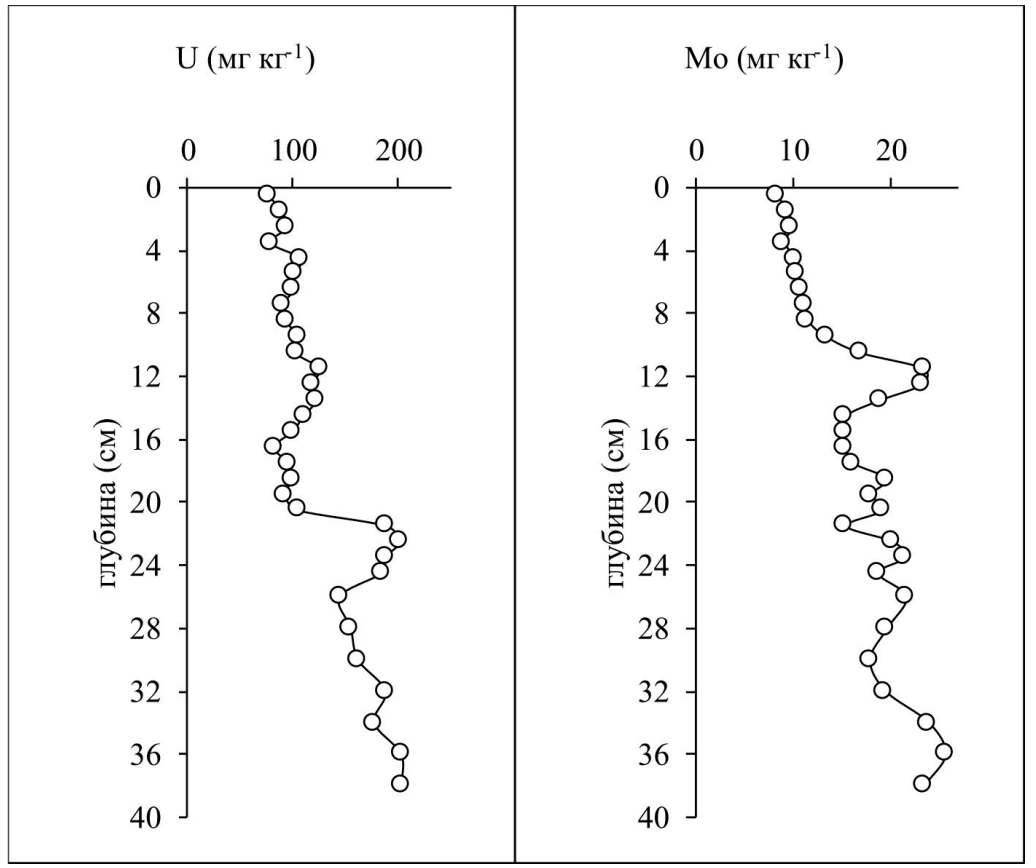

Рис. 4. Вертикальное распределение урана и молибдена в колонке ДО оз. Северного (г. Мурманск).

Fig. 4. Vertical distribution of uranium and molybdenum in the sediment core of the Lake Severnoe (Murmansk).

го, расположенного на выезде из г. Мурманска, связано с влиянием уранового оруденения магматических и метаморфических пород северо-западной части региона.

Исследование выполнено за счет гранта Российского научного фонда (проект № 19-77-10007).

\section{Литература}

1. Даувальтер В.А., Терентьев П.М., Денисов Д.Б., Удачин В.Н., Филиппова К.А., Борисов А.П. Реконструкция загрязнения территории полуострова Рыбачий Мурманской области тяжелыми металлами // Труды Ферсмановской научной сессии ГИ КНЦ РАН. 2018. № 15. С. 441-444.

2. Миронов Ю.Б., Лебедева Г.Б., Пуговкин А.А. Поверхностные урановые месторождения гумидной климатической зоны земли // Региональная Геология и Металлогения. 2015. № 63. С. 68-76.

3. Моисеенко Т.И., Даувальтер, В.А., Ильяшук, Б.П., Каган, Л.Я., Ильяшук, Е.А. Палеоэкологическая реконструкция антропогенной нагрузки // Доклады АН. 2000. Т. 370. № 1. С. 115-118.

4. Слуковский 3.И. Микроэлементый состав донных отложений малых озер как индикатор возникновения экологических рисков в условиях урбанизированной среды Республики Карелии // Водное хозяйство России. 2018. № 6. С. 70-82.

5. Слуковский 3.И., Даувальтер В.А. Морфология и состав техногенных частиц донных отложений оз. Нюдъявр, Мурманская область // Записки РМО. 2019. № 3. С. 102-117.

6. Escobar J., Whitmore T.J., Kamenov G.D., Riedinger-Whitmore M.A. Isotope record of anthropogenic lead pollution in lake sediments of Florida, USA // Journal of Paleolimnology. 2013. V. 49 (2). P. 237-252.

7. Kuwae M., Tsugeki N.K., Agusa T., Toyoda K., Tani Y., Ueda S., Tanabe S., Urabe J. Sedimentary records of metal deposition in Japanese alpine lakes for the last 250years: Recent enrichment of airborne $\mathrm{Sb}$ and $\mathrm{In}$ in East Asia // Science of the Total Environment. 2013. N. 442. P. 189-197.

8. Wedepohl K.H. The composition of the continental crust // Geochimica et Cosmochimica Acta. 1995. V. 59. N. 7. P. 1217-1232. 